\title{
The Influence of Abnormal Segregation Band on Mechanical Properties of Hot Rolled Ferrite/Pearlite Steel Plate
}

\author{
Rui Feng*, Benkui Gong, Hongwei Cui, Yaokun Pan, Jiahui Bao \\ School of Materials Science and Engineering, Shandong University of Technology, Zibo, China \\ Email: ^^fengrui1986@163.com
}

How to cite this paper: Feng, R., Gong, B.K., Cui, H.W., Pan, Y.K. and Bao, J.H. (2018) The Influence of Abnormal Segregation Band on Mechanical Properties of Hot Rolled Ferrite/Pearlite Steel Plate. Materials Sciences and Applications, 9, 81-91. https://doi.org/10.4236/msa.2018.91006

Received: November 24, 2017

Accepted: January 7, 2018

Published: January 10, 2018

Copyright $\odot 2018$ by authors and Scientific Research Publishing Inc. This work is licensed under the Creative Commons Attribution International License (CC BY 4.0). http://creativecommons.org/licenses/by/4.0/

\begin{abstract}
In order to further reveal the influence of abnormal segregation band on mechanical properties of hot rolled ferrite/pearlite steel plate, especially on laminated tensile fracture, the experimental method of delamination tension was adopted. In this paper, the thin tensile samples with $3 \mathrm{~mm}$ thickness from the surface, $1 / 4$ positions and center along the thickness orientation of test plate were measured, also the relationship between microstructure and mechanical properties was probed. The results show that the center region of hot rolled ferrite/pearlite steel plate exists granular bainite and ferrite mixed grains, which leads to lower plasticity and toughness of this region. During the tensile process, microcracks are generated and extended at the center of steel plate due to the inconsistency of deformation and fracture on the adjacent structures, finally leading to laminated fracture of steel plate.
\end{abstract}

\section{Keywords}

Ferrite/Pearlite Steel Plate, Segregation, Microstructure, Laminated Fracture

\section{Introduction}

Currently, the hot rolled ferrite/pearlite steel with strength of about $400 \mathrm{MPa}$ is made from tracing carbonization-easily-form elements $\mathrm{Nb}, \mathrm{V}$, Ti addition to the ordinary low carbon steel, which obtains good combination of strength and toughness through the fine grain strengthening and the precipitation strengthening [1] [2]. It has been widely used in ship building, mining machine and building industry [3] [4]. The banded structure along the rolling direction is prevalent in hot rolled ferrite/pearlite steel, which worsens the horizontal toughness and the section shrinkage [5]. The abnormal segregation band is a 
kind of special morphology of banded structure, which seriously worsens the mechanical properties of steel plates [6]. Daisuke et al. [7] found that the band of Mn segregation and MnS promoted hydrogen-assisted cracking in the tempered martensitic steel, caused longitudinal cracking which was a mechanically unpreferential direction in homogeneous situations. Tanaka [8] suggested that MnS inclusions by segregation of impurity atoms initiated a crack and intergranular failures occurred along prior austenite grain boundaries, which might cause lamination. Shanmugam et al. [9] found that continuous splits, especially laminated fractures were due to the continuous ordered layer of ferrite and pearlite, and elongated non-metallic inclusion. Many researchers [10] [11] have confirmed that banding is primarily due to abnormal segregation of manganese and non-metallic inclusions. Therefore, the influence of abnormal segregation band on mechanical properties of steel plates has aroused widespread concern of scholars at home and abroad [12] [13].

It is difficult to measure mechanical properties of the abnormal segregation band of steel plates with conventional methods. To probe the influence of abnormal segregation band on mechanical properties of steel plates, especially the relationship between the band and laminated tensile fracture, the tensile test using thin samples at different positions along the thickness orientation of steel plates was firstly applied.

\section{Experimental Methods}

The experimental steel

(Fe-0.15 C-0.32 Si-1.48 Mn-0.034 Nb-0.004 V-0.013 Ti-0.038 Als (in wt\%)) was commercial hot rolled steel plate with $20 \mathrm{~mm}$ thickness. The values of tensile strength, yield strength, elongation percentage and impact toughness obtained from tensile and Charpy V-notch tests for experimental steel are $580 \mathrm{MPa}\left(R_{\mathrm{m}}\right)$, $400 \mathrm{MPa}\left(R_{\mathrm{P} 0.2}\right), 21 \%(A)$ and $84.9 \mathrm{~J}\left(K V_{2}\left(0^{\circ} \mathrm{C}\right)\right)$. The production technology applied is controlled rolling and controlled cooling. The continuous casting slab with $270 \mathrm{~mm}$ thickness is fabricated by vacuum induction melting and homogenized at $1120^{\circ} \mathrm{C}-1180^{\circ} \mathrm{C}$ for $210-240 \mathrm{~min}$, followed by hot rolling between $1120^{\circ} \mathrm{C}-850^{\circ} \mathrm{C}$ into the final thickness. The start and end cooling temperature is $810^{\circ} \mathrm{C}-830^{\circ} \mathrm{C}$ and $600^{\circ} \mathrm{C}-620^{\circ} \mathrm{C}$ respectively, and the cooling rate is $7^{\circ} \mathrm{C}-$ $8^{\circ} \mathrm{C} / \mathrm{s}$.

Nikon Epiphot300 optical microscope (OM), SU-70 Field Emission Scanning Electron Microscope (SEM) and FEI Tecnai G2F30S-Twin Transmission Electron microscopy (TEM) were used to analyze the microstructure and fracture morphology of test plate. HV1-10A Vickers Hardness Tester was applied to measure Vickers hardness at different positions of the plate along the thickness orientation. To detect the sensitivity of structure on impact properties, the $10 \times$ $10 \times 55 \mathrm{~mm}$ impact samples were cut from the rolling direction, and the normal directions of $\mathrm{V}$-notches were respectively corresponded to the surface, 1/4 position $(1 / 4 \mathrm{t})$ and center along the thickness orientation. The tensile test of thin 
samples with thickness of $3 \mathrm{~mm}$ from the surface, $1 / 4$ position $(1 / 4 \mathrm{t})$ and center along the thickness orientation were used to measure the mechanical properties of corresponding positions.

\section{Results}

\subsection{Microstructure of Test Plate}

The microstructure of test plate is ferrite + pearlite, and the ferrite grains are equiaxed and homogeneous distributed. The ferrite grains become coarser from the surface to the center along the thickness orientation. The pearlite close to the center gradually shows zonal distribution morphology, with the zonal space of about $30 \mu \mathrm{m}$. Besides, the abnormal segregation band appears at the center of test plate, as shown by the arrow in Figure 1(a). For further study of the abnormal segregation band, the microstructure of worn surface of tensile fracture was observed by SEM, as shown in Figure 1(b). The band shows surface relief morphology, and it is mainly granular bainite.

Dozens of vision fields were chosen randomly at the surface, 1/4 position and center of test plate, aiming at measuring about 500 ferrite grains, and the grain size distribution is shown in Figure 2. It is found that the ferrite grain size at the surface and $1 / 4$ position are $7-9 \mu \mathrm{m}$ and $8-10 \mu \mathrm{m}$ respectively, and the ferrite grains become coarser as it approaches to the center. At the center of test plate, there are 3 - 3.5 degrees difference of grain size, and the coarse grains are approximately $40 \mu \mathrm{m}$ mixing with fine grains.
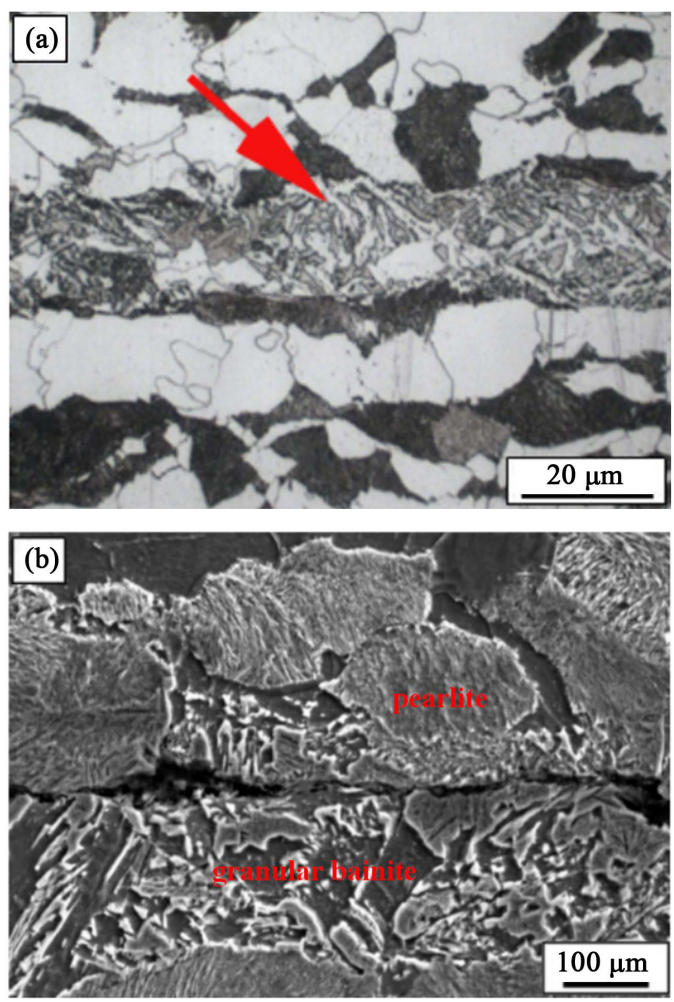

Figure 1. Microstructure of abnormal segregation band. 


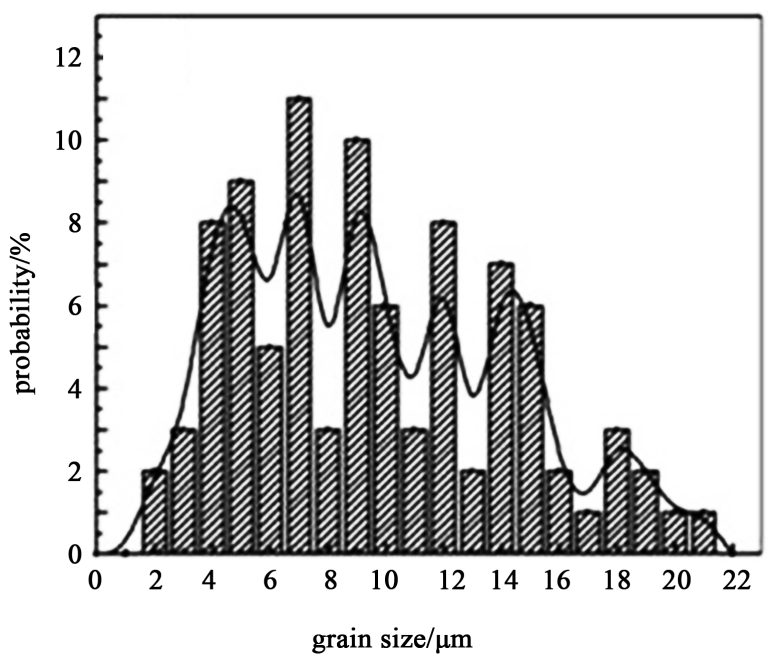

(a)

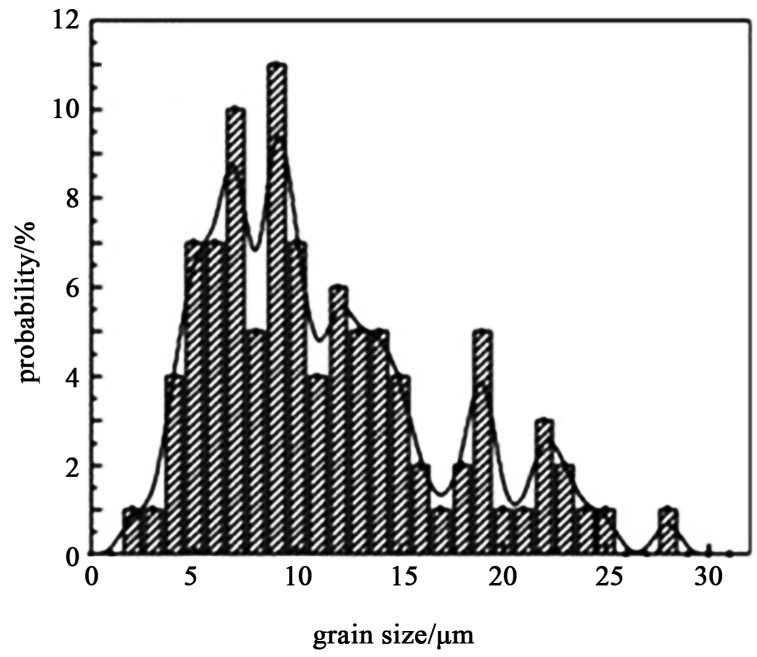

(b)

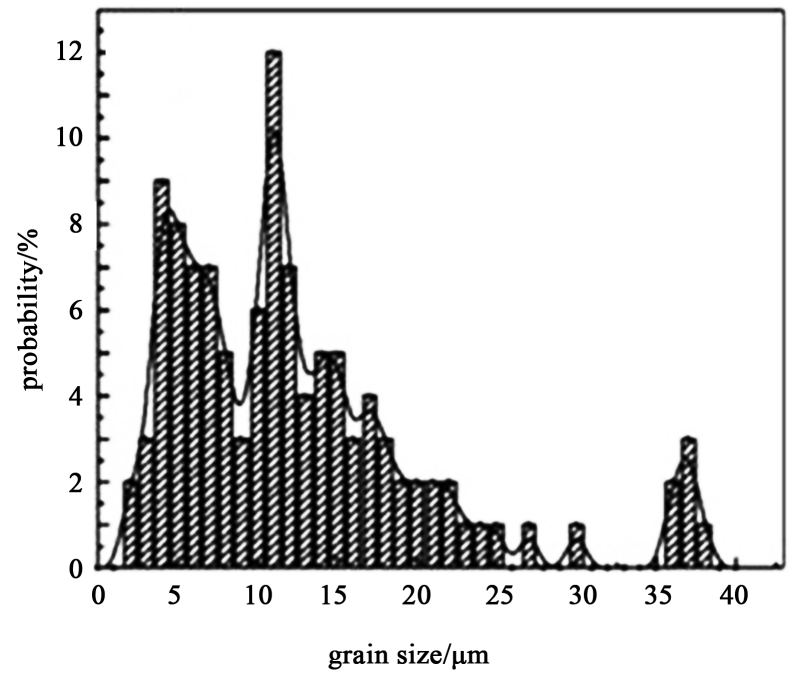

(c)

Figure 2. Distribution of grain size at different positions of test plate. (a) Surface; (b) 1/4; (c) Center. 
The distribution of $\mathrm{Mn}$ in the ferrite band, pearlite band and abnormal segregation band was measured by Energy Dispersive Spectrometer (EDS). Through calculating the average value of multiple plane scanning, we found that the content of $\mathrm{Mn}$ element in the ferrite was $0.96 \%$, the content in the pearlite band was $1.94 \%$, and the content in the abnormal segregation was $2.86 \%$. It can be concluded that the distribution of Mn element in these bands is not uniform, the abnormal segregation and pearlite bands with higher Mn content, which are rich in $\mathrm{Mn}$, while the ferrite bands with lower Mn content, which are poor in Mn. Along the thickness orientation of test plate, the average fractions of ferrite (56\%), pearlite (29\%) and abnormal segregation band (15\%) were measured by means of quantitative metallographic method. According to the microstructure and $\mathrm{Mn}$ distribution, the content of $\mathrm{Mn}$ is $1.529 \%$ by theoretical calculation, which is quite close to the measured data. The segregation of Mn at the center of the steel plate is the root cause of the formation of granular bainite [14].

\subsection{Mechanical Properties of Test Plate}

Table 1 represents the tensile properties and average grain size of thin samples obtained from different positions of the plate along the thickness orientation. It is found that mechanical properties of the surface and $1 / 4$ position is relatively high, while the tensile properties of the center is obviously lower than that of steel plate overall. The results of Vickers hardness test show that the Vickers hardness of the center (coarse grain zone) is $34 \mathrm{HV} 0.1$ lower than that of the surface (fine grain zone), as shown in Figure 3. According to the conversion relation of Vickers hardness and yield strength [15], the yield strength of coarse grain zone and fine grain zone differs about $100 \mathrm{MPa}$, which is close to the value

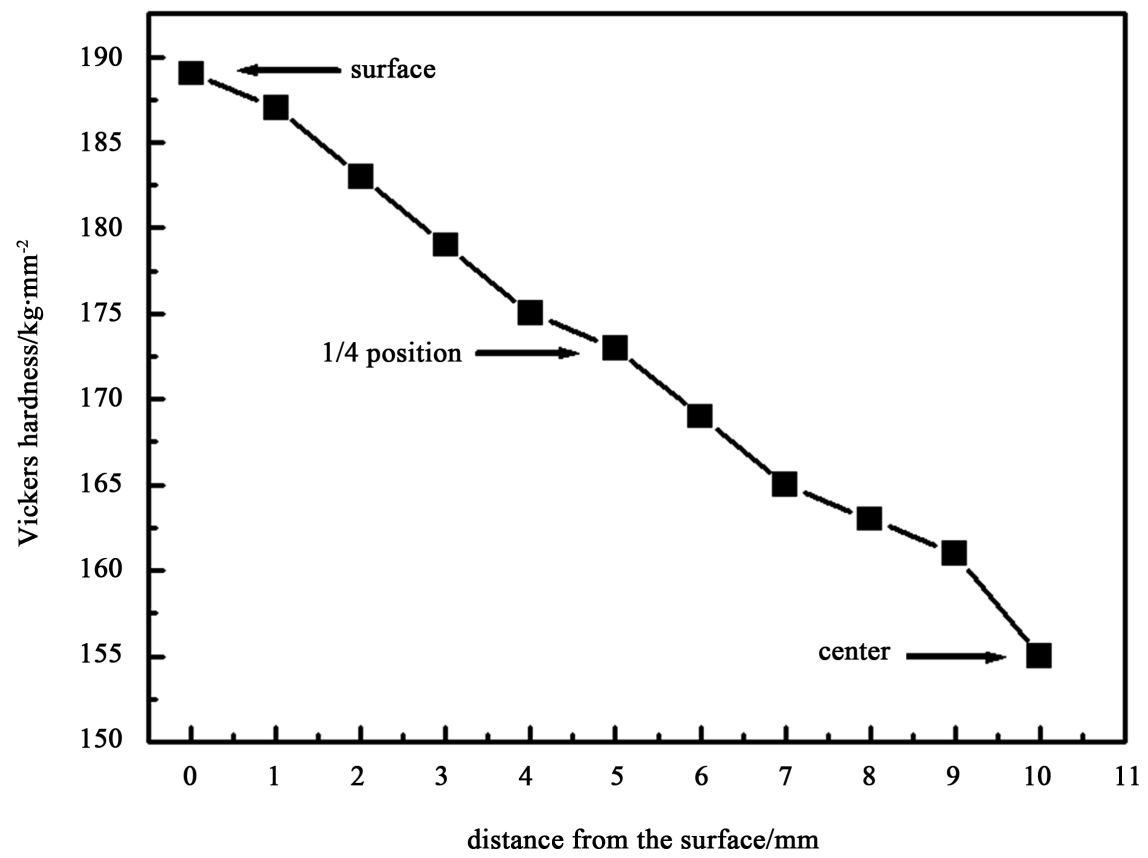

Figure 3. Vicker hardness at different positions of test plate. 
Table 1. Tensile properties at different positions of test plate.

\begin{tabular}{ccccc}
\hline Analyzing zone & $R_{\mathrm{P} 0.2} / \mathrm{MPa}$ & $R_{\mathrm{m}} / \mathrm{MPa}$ & $A / \%$ & $d / \mu \mathrm{m}$ \\
\hline Surface & 460 & 620 & 22.0 & 7.6 \\
$1 / 4$ position & 435 & 585 & 21.0 & 8.5 \\
Center & 375 & 495 & 20.5 & 11.2 \\
\hline
\end{tabular}

measured in this study. Based on the dates in Table 1 and interrelated counting, we figured out that yield strength of different positions is inversely proportional to the average grain size, and they are in keeping with Hall-Petch relation [16]. The coarse ferrite grain and a certain degree of mixed grain will lead to mechanical properties of the center lower than that of the surface and $1 / 4$ position of test plate.

\subsection{Morphology of Tensile and Impact Fractures of Test Plate}

The tensile fracture surface of test plate shows typical laminated morphology, as shown in Figure 4, and the laminated region is coincidence with the abnormal segregation band region. The center of the fracture (A zone) presents bright white, where appears several non-continuous cracks, one of them is almost throughout the entire section. The sections on both sides of the cracks are parallel but not in the same plane. The $1 / 4$ position and edge of the fracture present gray, which are labeled $\mathrm{B}$ zone and $\mathrm{C}$ zone respectively. The higher magnification morphology of A, B, C zone is shown in Figure 5. The A zone is located at the center of test plate, where presents stacked steps with regular arrangement and unequal size appearance. The obvious river patterns can be observed on the steps, and each river pattern stops at the lamination of the steps. The typical quasi-cleavage morphology and clear tearing ridge are observed on the steps, which indicate that the grain size of this region is abnormally coarser. The B zone is located at the $1 / 4$ position of test plate, where presents large dimples. The spherical second phase particles were observed at the bottom of individual dimples, which shows the toughness of B zone is obviously better than that of A zone. C zone is located near the surface of test plate, where presents obvious plastic deformation. The typical tearing dimples of parachute trends were observed at this zone. There are some small tearing dimples gathering near the large tearing dimples, and slipping waves pointing to the crack sources.

The impact fracture at the center of test plate also appears the "laminated" morphology, as shown in Figure 6. While the impact fractures of the surface and $1 / 4$ position do not appear the "laminated" morphology, they are typical ductile fracture. The radiating area of impact fracture at the center is typical cleavage fracture (" $A$ " region), while both sides are typical dimple morphology ("B" region). The cleavage fracture region is corresponding with the abnormal segregation band of granular bainite, and they are similar in width. The dimple morphology on both sides corresponds to the normal ferrite/pearlite structure, which indicates that the plasticity and toughness of this region is better than that 


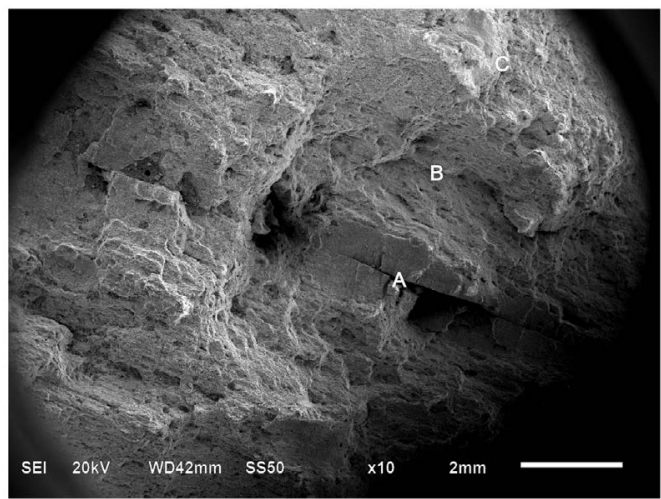

Figure 4. Morphology of laminated tensile fracture of the test plate.

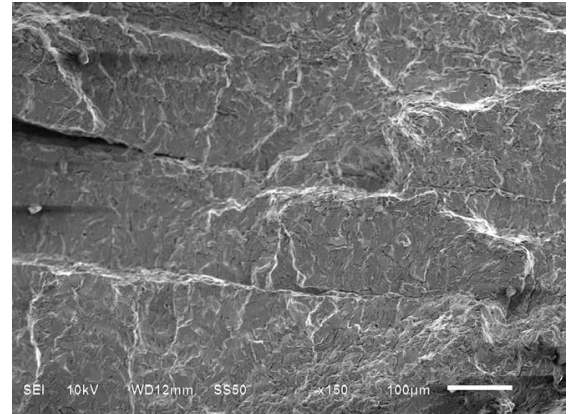

(a)

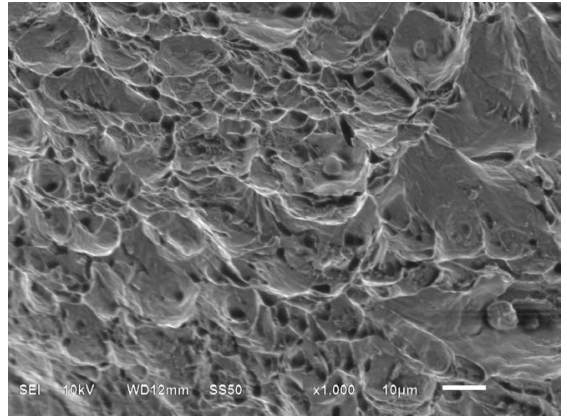

(c)

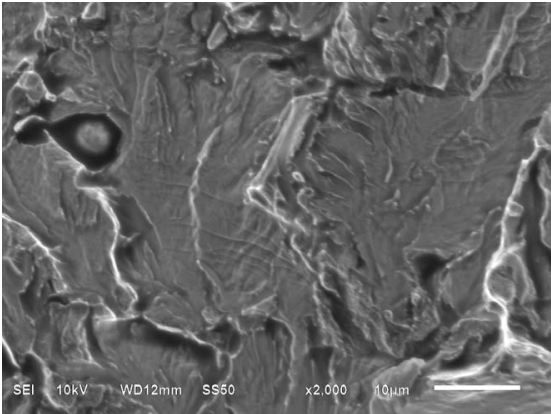

(b)

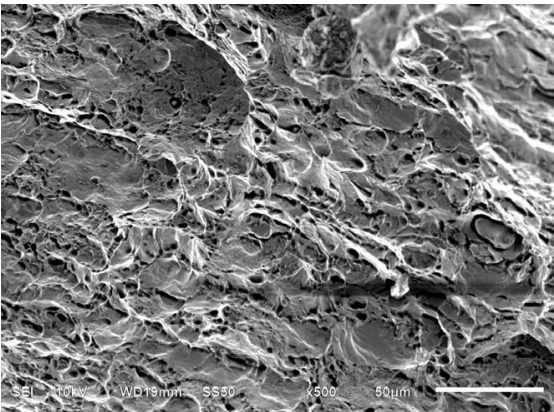

(d)

Figure 5. Morphology of laminated tensile fracture at different zones. (a) and (b) A zone; (c) B zone; (d) C zone.

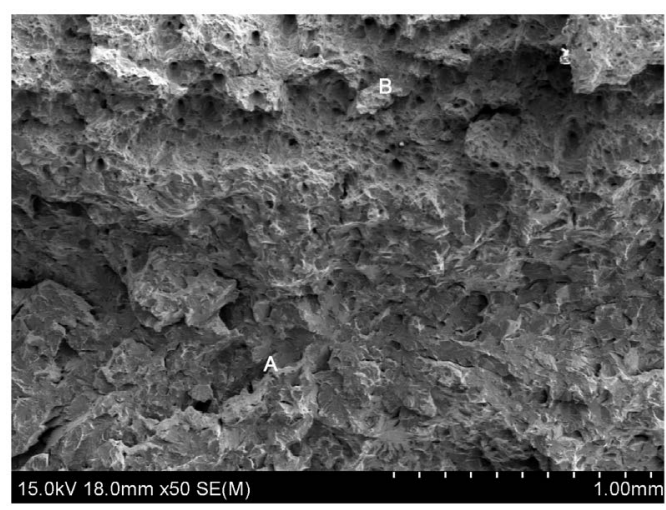

Figure 6. Morphology of laminated impact fracture at the center of test plate. 
of the center. From the above analysis, the granular bainite in the abnormal segregation band region lead to mechanical properties worsening of the center of test plate.

\section{Discussion}

From the above analysis, the granular bainite and ferrite mixed grains occurred in the abnormal segregation band region at the center of test plate, which are the vital reasons for the worsening of mechanical properties and laminated fracture. The banded microstructure is a very common structure of hot rolled plates, which is due to the uneven distribution of alloy elements (mainly $\mathrm{Mn}$ ). These findings are from most of the published reports. The uneven distribution of $\mathrm{Mn}$ in the steel plates originated from the continuous casting billets. The more severe composition segregation or other improper process can cause abnormal segregation band at the center of the steel plates. The granular bainite band at the center of hot rolled ferrite/pearlite is a typical abnormal segregation band.

Firstly, considering the properties of bainite, when the strain occurs to the segregation band of granular bainite at the center of hot rolled ferrite/pearlite steel, the structure and stress transfer manner of bainite and matrix are different. Therefore, the tiny holes and cracks are apt to generate at their boundaries [17]. Secondly, based on the theory of microstructure and strength [18], the elongation percentage of ferrite of low carbon steel is $40 \%$, and the elongation percentage of pearlite is $10 \%$, while the elongation percentage of bainite is very low. Therefore, bainite in the abnormal segregation band region has higher strength, but lower plasticity and toughness than ferrite and pearlite, which has the tendency of firstly fracture at the same tensile stress. The microcracks are inclined to form and extend in the bainite, or boundaries between bainite and matrix, which eventually lead to separation of the fracture, that is the laminated fracture.

Studies have found that the ferrite in the abnormal segregation band region exists a certain degree of mixed grain due to chemical composition segregation [19] and improper control of production technology [20]. According to the strength expression formula raised by Pickering [16], the strength of matrix is express as: $\sigma_{G}=53.9+17.402 d^{-1 / 2}$, and $d$ is ferrite average grain size. From the formula, the strength of matrix is inversely proportional to ferrite average grain size; $\sigma_{G}$ of coarse grain zone is lower than that of fine grain zone. The average grain size of coarse grain zone is $37 \mu \mathrm{m}$, while that of fine grain zone is $10 \mu \mathrm{m}$, as shown in Figure 2(c). According to theoretical calculation, the difference of strength between the coarse zone and fine grain zone is $83.55 \mathrm{MPa}$. The difference in strength leads to stress concentration and dislocation pile-up (as shown in Figure 7) at boundaries of coarse grain zone and fine grain zone, which may induce microcracks [21] [22]. Based on the lowest energy principle of crack propagation [23], the resistance of crack propagation in coarse grain region is smaller. Therefore, it is apt to be the lower energy paths for crack propagation and connectivity, creating conditions for laminated tensile fracture. Moreover, 


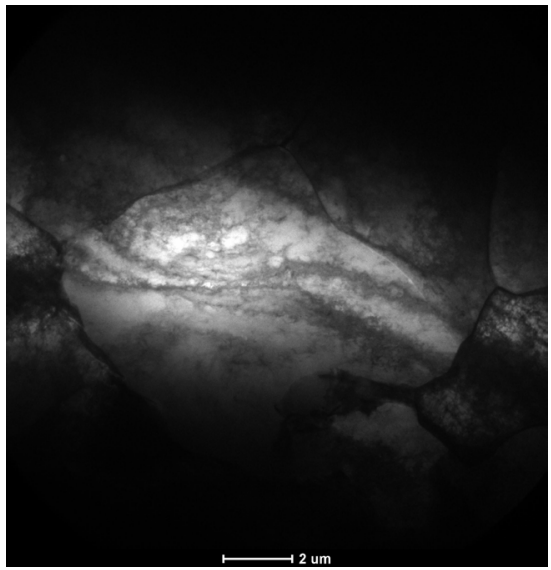

(a)

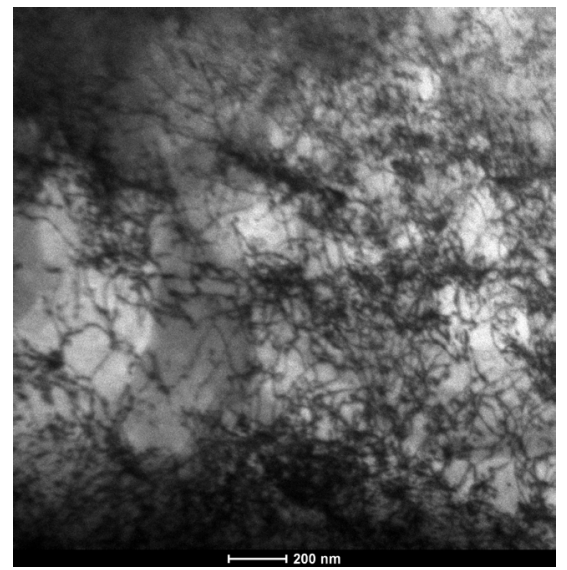

(b)

Figure 7. Dislocations at the boundary between coarse grain zone and fine grain zone (TEM).

due to mixed grain and relatively coarse grain at the center, tensile strength of this region is obviously lower than that of the surface and $1 / 4 \mathrm{t}$. When subjected to the tensile stress, the center region firstly yields and steps into plastic deformation stage, while the surface region is still in elastic deformation stage. The inconsistency of deformation and fracture causes laminated tensile fracture.

\section{Summary}

At the center region, hot rolled ferrite/pearlite steel plate exists granular bainite and ferrite mixed grain, which leads to lower plasticity and toughness of this region. During the tensile process, microcracks are generated at the center region due to the inconsistency of deformation and fracture of the adjacent structures, finally leading to laminated fracture of the hot rolled ferrite/pearlite steel plate.

\section{Acknowledgements}

This work was financially supported by the Natural Science Foundation of Shandong Province (ZR2015PE002).

\section{References}

[1] Wang, L., Tang, D. and Song, Y. (2017) Prediction of Mechanical Behavior of Ferrite-Pearlite Steel. Journal of Iron and Steel Research, International, 3, 321-327. https://doi.org/10.1016/S1006-706X(17)30046-8

[2] Fernández, J., Illescas, S. and Guilemany, J.M. (2007) Effect of Microalloying Elements on the Austenitic Grain Growth in a Low Carbon HSLA Steel. Materials Letters, 61, 2389-2392. https://doi.org/10.1016/j.matlet.2006.09.021

[3] Al-Abbasi, F.M. (2010) Micromechanical Modeling of Ferrite-Pearlite Steels. Materials Science and Engineering: A, 527, 6904-6916. https://doi.org/10.1016/j.msea.2010.07.045

[4] Allain, S. and Bouaziz, O. (2008) Microstructure Based Modeling for the Mechanical Behavior of Ferrite-Pearlite Steels Suitable to Capture Isotropic and Kinematic Hardening. Materials Science and Engineering: A, 496, 329-336. 
https://doi.org/10.1016/j.msea.2008.06.009

[5] Zhang, X.C., Wang, Y., Yang, J., Qiao, Z.X., Ren, C.H. and Chen, C. (2016) Deformation Analysis of Ferrite/Pearlite Banded Structrue under Uniaxial Tension Using Digital Image Correlation. Optics and Lasers in Engineering, 85, 24-28. https://doi.org/10.1016/j.optlaseng.2016.04.019

[6] Feng, R., Li, S.L., Zhu, X.D. and Ao, Q. (2015) Microstructural Characterization and Formation Mechanism of Abnormal Segregation Band of Hot Rolled Ferrite/Pearlite Steel. Journal of Alloys and Compounds, 646, 787-793.

https://doi.org/10.1016/j.jallcom.2015.05.128

[7] Sasaki, D., Koyama, M. and Noguchi, H. (2015) Factors Affecting Hydrogen-Assisted Cracking in a Commercial Tempered Martensitic Steel: Mn Segregation, MnS, and the Stress State around Abnormal Cracks. Materials Science and Engineering: $A, 640,72-81$. https://doi.org/10.1016/j.msea.2015.05.083

[8] Tanaka, T. (1981) Controlled Rolling of Steel Plate and Strip. Int Metals Rev, 26, 185-212.

[9] Shanmugam, P. and Pathak, S.D. (1996) Some Studies on the Impact Behavior of Banded Microalloyed Steel. Engineering Fracture Mechanics, 53, 991-1005. https://doi.org/10.1016/0013-7944(95)00159-X

[10] Karimi, Y., Hossein Nedjad, S., Miyamoto, G., Shirazi, H. and Furuhara, T. (2017) Banding Effects on the Process of Grain Refinement by Cold Defomation and Recrystallization of Acicular C-Mn Steel. Materials Science and Engineering: A, 697, 1-7. https://doi.org/10.1016/j.msea.2017.05.006

[11] Choudhary, S.K., Ganguly, S., Sengupta, A. and Sharma, V. (2017) Solidification Morphology and Segregation in Continuously Cast Steel Slab. Journal of Materials Processing Technology, 243, 312-321. https://doi.org/10.1016/j.jmatprotec.2016.12.030

[12] Mendoza, R., Alansis, M., Perez, R., Alvarez, O., Gonzalez, C. and Juarez-Islas, J.A. (2002) On the Processing of Fe-C-Mn-Nb Steels to Produce Plates for Pipelines with Sour Gas Resistance. Materials Science and Engineering. A, 337, 115-120. https://doi.org/10.1016/S0921-5093(02)00009-6

[13] Ma, J., Zhang, B., Xu, D.K., Han, E.-N. and Ke, W. (2010) Effects of Inclusion and Loading Direction on the Fatigue Behavior of Hot Rolled Low Carbon Steel. International Journal of Fatigue, 32, 1116-1125. https://doi.org/10.1016/j.ijfatigue.2009.12.005

[14] Fang, H.-S., Feng, C., Zheng, Y.-K., Yang, Z.-G. and Bai, B.-Z. (2008) Creation of Air-Cooled Mn Series Bainitic Steels. Journal of Iron and Steel Research International, 15, 01-09. https://doi.org/10.1016/S1006-706X(08)60257-5

[15] Tekkaya, A.E. and Lange, K. (2000) An Improved Relationship between Vickers Hardness and Yield Stress for Cold Formed Materials and Its Experimental Verification. CIRP Annals, 49, 205-208. https://doi.org/10.1016/S0007-8506(07)62929-1

[16] Lehto, P., Remes, H., Saukkonen, T., Hänninen, H. and Romannoff, J. (2014) Influence of Grain Size Distribution on the Hall-Petch Relationship of Welded Structural Steel. Materials Science and Engineering: A, 592, 28-39.

https://doi.org/10.1016/j.msea.2013.10.094

[17] Schino, A.D. and Guarnaschelli, C. (2009) Effect of Microstructure on Cleavage Resistance of High-Strength Quenched and Tempered Steels. Materials Letters, 63, 1968-1972. https://doi.org/10.1016/j.matlet.2009.06.032

[18] Zare, A. and Ekrami, A. (2011) Influence of Martensite Volume Fraction on Tensile Properties of Triple Phase Ferrite-Bainite-Martensite Steels. Materials Science and 
Engineering: $A$, 530, 440-445. https://doi.org/10.1016/j.msea.2011.09.108

[19] Grange, R.A. (1971) Effect of Microstructural Banding in Steel. Metallurgical and Materials Transactions B, 2, 417-426. https://doi.org/10.1007/BF02663328

[20] Eghbali, B. (2007) EBSD Study on the Formation of Fine Ferrite Grains in Plain Carbon Steel during Warm Deformation. Materials Letters, 61, 4006-4010. https://doi.org/10.1016/j.matlet.2007.01.019

[21] Habib, K., Koyama, M., Tsuchiyama, T. and Noguchi, H. (2017) Fatigue Crack Non-Propagation Assisted by Nitrogen-Enhanced Dislocation Planarity in Austenitic Stainless Steels. International Journal of Fatigue, 104, 158-170. https://doi.org/10.1016/j.ijfatigue.2017.07.019

[22] Terentyev, D., Bakaev, A., Serra, A., Pavia, F., Baker, K.L. and Anento, N. (2018) Grain Boundary Mediated Plasticity: The Role of Grain Boundary Atomic Structure and Thermal Activation. Scripta Materialia, 145, 1-4. https://doi.org/10.1016/j.scriptamat.2017.10.002

[23] Chapetti, M.D., Miyata, H., Tagawa, T., Miyata, T. and Fujioka, M. (2005) Fatigue Crack Propagation Behaviour in Ultra-Fine Grained Low Carbon Steel. International Journal of Fatigue, 27, 235-243. https://doi.org/10.1016/j.ijfatigue.2004.07.004 